\title{
A New Defense of Hedonism about Well-Being
}

\author{
BEN BRAMBLE \\ Lund University
}

\begin{abstract}
According to hedonism about well-being, lives can go well or poorly for us just in virtue of our ability to feel pleasure and pain. Hedonism has had many advocates historically, but has relatively few nowadays. This is mainly due to three highly influential objections to it: The Philosophy of Swine, The Experience Machine, and The Resonance Constraint. In this paper, I attempt to revive hedonism. I begin by giving a precise new definition of it. I then argue that the right motivation for it is the 'experience requirement' (i.e., that something can benefit or harm a being only if it affects the phenomenology of her experiences in some way). Next, I argue that hedonists should accept a felt-quality theory of pleasure, rather than an attitude-based theory. Finally, I offer new responses to the three objections. Central to my responses are (i) a distinction between experiencing a pleasure (i.e., having some pleasurable phenomenology) and being aware of that pleasure, and (ii) an emphasis on diversity in one's pleasures.
\end{abstract}

\section{Introduction}

Lives can go well or poorly for individuals. What makes this so? According to hedonism, the answer is just pleasures and pains. ${ }^{1}$ Hedonism has many advocates in the history of philosophy. ${ }^{2}$ But it has relatively few nowadays (in print, at least). ${ }^{3}$ This is mainly due to three highly influential objections to it, each of which is considered by many to be decisive: The Philosophy of Swine, The Experience Machine, and The Resonance Constraint.

1. In this essay, I will use 'pain' to refer to unpleasurable experiences more generally.

2. These include Democritus, Aristippus, Epicurus, Jeremy Bentham, and J. S. Mill. Others whose views seem at times to come close to hedonism include Socrates, Aristotle, Locke, Hobbes, Hume, Kant, and Sidgwick.

3. Notable exceptions include Feldman (2004), Crisp (2006), Heathwood (2006), and Bradley (2009). Note that Heathwood counts as both a hedonist and a desire-based theorist of well-being due to his desire-based theory of pleasure. 
In this paper, I will provide a new defense of hedonism. I will start by giving a precise new definition of it (Section 2). I will then explain what I consider to be the most compelling motivation for it (Section 3). Next, I will argue that hedonism should be paired with a felt-quality theory of pleasure, rather than an attitude-based one (Section 4). Finally, I will offer new responses to the three objections mentioned above (Section 5, Section 6, and Section 7). I will conclude by neatly setting out the version of hedonism we will have ended up with, and summarising its key virtues (Section 8).

\section{Defining Hedonism}

Philosophers often distinguish between two kinds of well-being:

1. Momentary well-being, or how well off someone was at a particular moment in her life (say, the present moment, or 7.34am, July 10, 1993, etc.), and

2. Extended-period well-being, or how well off someone was during a particular period or stretch of time-say, a day, a week, a month, an entire chapter of her life, or (in the limiting case) her life considered as a whole (lifetime well-being). ${ }^{4}$

In this paper, I will assume that lifetime well-being is the normatively significant notion. That is, only lifetime well-being is itself worth promoting for someone's sake, and an ultimate source of self-interested reasons for someone. The other kinds of well-being, to the extent that they matter for someone at all, matter only derivatively, by having implications (either constitutive or causal) for her lifetime wellbeing. ${ }^{5}$ Consequently, I will treat the following as the fundamental question in the philosophy of well-being:

What determines the various respects in which someone's life considered as a whole went well or poorly for her?

Given this way of understanding what is at issue, a natural definition of hedonism is as the view that the various respects in which someone was well or

4. For a small sample of those who draw this distinction, see Bradley (2009), Bramble (2014), Broome (2004), Brink (2010), Campbell (2015), Dorsey (2009), Feldman (2004), Griffin (1986), Heathwood (2011), Kauppinen (2011), McMahan (2002), Portmore (2007), Raibley (2012), and Velleman (2000).

5. See Griffin (1986), Brink (2010), and Bramble (2016). 
poorly off in her life considered as a whole are fully determined by her pleasures and pains. More precisely:

Hedonism. Any two beings who are identical in what pleasures and pains they felt during their lives must also be identical in any respects in which they were well and poorly off in their lives considered as wholes.

It may be objected that this definition is not precise enough, for it counts what Feldman refers to as dolorism-i.e., "the view that pain is the Good and pleasure is the Bad" (Feldman 2004: 182) - as a version of hedonism. However, like Feldman (whose own proposed definition of hedonism shares this implication), I do not find this too worrying. If you are worried by it, feel free to add to the above definition "where, in some suitable sense, pleasure is the good and pain is the bad". 6

Finally, I will assume here the following conception of benefiting and harming:

Benefiting and Harming. To benefit somebody is to make her better off in some respect in her life considered as a whole than she would otherwise have been. To harm somebody is to make her worse off in some respect in her life considered as a whole than she would otherwise have been.7

To work out whether some particular event benefited a person, it is necessary and sufficient to compare her actual whole life with the whole life she would have had had this event not occurred, and see if she is better off in any respect in the former than in the latter.

On this assumption, hedonism implies the following view about benefiting and harming (which will be important later on, in Section 3):

Hedonism about Benefiting and Harming $(\mathrm{HBH})$ : Benefiting and harming just consist in affecting pleasures and pains in various ways.

Now that it is clear what I think we should mean by hedonism, let us turn to the question of why hedonism is attractive.

\section{The Appeal of Hedonism}

Many motivations have been offered for hedonism. Most of these, it is fair to say, are not very convincing. ${ }^{8}$ But one seems to me highly compelling:

6. To further sharpen this definition would needlessly complicate matters to come.

7. While popular, this comparativist conception of benefiting and harming is not without its critics. See, for example, Harman (2004) and Shriffin (1999).

8. For an excellent discussion, see Dorsey (2011). 
The Experience Requirement. Something can benefit or harm a being only if it affects her experiences in some way-specifically, their phenomenology (or 'what it is like' to be having them). ${ }^{9}$

If the experience requirement is true, then hedonism seems likely to be true as well. This is because:

1. If things must affect someone's experiences in order to benefit or harm her, this is likely because benefiting and harming just consist in affecting people's experiences in various ways.

2. If benefiting and harming just consist in affecting people's experiences in various ways, this is likely because they just consist in affecting people's pleasures and pains specifically (HBH from above).

I will take (2) for granted. But I want to consider an important objection to (1). It may be suggested that, while it is indeed necessary in order to benefit or harm someone that one affect her experiences in some way, more is required. For example, it may be that in order to benefit someone, one must give her, not only a pleasure, but, say, actual fame (or friendship, health, success, desire-satisfaction, or whatever it may be). Such a view does not count as hedonistic on my definition (since, according to such a view, benefiting and harming do not just consist in affecting people's pleasures and pains in various ways), but it seems to satisfy the experience requirement.

However, on closer inspection, such a view does not in fact satisfy this requirement. Suppose that somebody, having been given pleasure and fame (and so, on such a view, having been benefited) then loses the fame, but retains the pleasure. On the view in question, the loss of this fame would constitute a harm to this person, since she no longer has both the pleasure and the fame. But her experiences need not have been affected in any way (if, for example, she was ignorant of the loss of her fame). So, on such a view, there could be benefits or harms without changes in experiences.

I will take it, then, that not only (2), but (1) also, is true. The crucial question now is Why believe the experience requirement? Many people (including myself) feel that something that has no effect on a person's experiences does not 'touch' or 'get to' this person in the sort of way required for something to benefit or harm someone. ${ }^{10}$ But many others claim not to have this intuition. ${ }^{11}$ Is there an

9. Here, I paraphrase Sumner (1996).

10. For useful discussion, see Sumner (1996) and Kagan (1992).

11. For discussion, see Kagan (1994). 
argument for the experience requirement that might sway these others? I believe there is. It is this:

1. If something could benefit or harm someone without affecting her experiences (say, fame, success, desire-satisfaction, or whatever it may be), then it could do so even after she is dead.

2. Nothing can benefit or harm us after we are dead (there can be no posthumous benefits or harms).

Therefore,

3. Nothing can benefit or harm someone without affecting her experiences.

Let me say something in defense of each premise, starting with (2). ${ }^{12}$ Consider Vincent Van Gogh, Emily Dickinson, Nick Drake, Emily Brontë, and John Kennedy Toole, each of whose lives were all-things-considered pretty unfortunate (or, at the very least, not especially fortunate) - full of loneliness, illness (physical and mental), fractured family relationships, and perhaps worst of all, a deep despair that came from knowing that their artistic works, to which they had devoted their lives, were almost totally unappreciated by their contemporaries. Each of them, however, went on to achieve tremendous posthumous success, fame, and desire-satisfaction (since each dearly wanted their works to be appreciated). Now, if posthumous events could be good or bad for one, then surely the truly enormous posthumous success, fame, or desire-satisfaction that these individuals achieved would mean that their lives were not so unfortunate after all. But it doesn't. (Intuitively, this is part of the reason their lives were tragic.) Therefore, there can be no posthumous benefits or harms. ${ }^{13}$

Now consider (1). The burden here seems clearly to be on those who would deny ( 1 ) to answer the following question:

If the contribution to our well-being of success, fame, desire-satisfaction, or whatever it is, does not depend on our experiences being affected,

12. This is necessary because, while many people find it simply obvious that there can be no posthumous benefits and harms, many philosophers claim to have the contrary intuition (and to have it quite forcefully). For a defense of the possibility of posthumous harms, see Lukas (2009).

13. This argument, to be sure, is not decisive. It is possible that posthumous events could be good or bad for us, but only ever slightly so. If this were true, then the posthumous success, fame, or desire-satisfaction of Van Gogh, Dickinson, etc., might be good for these people, even though their lives remain all-things-considered unfortunate. But in order to believe this, we would need some principled reason to believe that posthumous benefits and harms could only ever be slight. I cannot myself think of what such a reason could be. 
then why should it matter whether we are still alive or not for this contribution to be made?

Some have suggested that it is because death removes the subject, and without a subject there is no-one left to be harmed. However, even after death, there remains a subject in one sense: the person who once existed. If it is replied that this is insufficient, that there must continue to be a living, breathing being for there to be a subject of harm, then we are back with the original question: Why must one still exist in order to be harmed by things if their harming one does not require their affecting one's experiences?

The experience requirement, by contrast, provides a very natural explanation of why there can be no posthumous benefits and harms. What, after all, is death? On a plausible conception, it is just the permanent cessation of one's experiences. Death, then, we can say, ends one's ability to be benefited and harmed precisely because it is the end of one's experiences, and benefiting and harming require affecting one's experiences.

I conclude that we have, in the experience requirement, a very powerful reason to believe hedonism.

\section{The Nature of Pleasure}

What should a hedonist say about the nature of pleasure and pain? There are two main competing theories: felt-quality and attitude-based ones. According to felt-quality theories,

some bit of phenomenology counts as a pleasure or a pain just in virtue of its phenomenology (i.e., 'what it is like' to be experiencing it). ${ }^{14}$

By contrast, attitude-based theories say that

some bit of phenomenology counts as a pleasure or a pain just in virtue of the subject's attitude toward it (e.g., whether it is liked, wanted, etc.). ${ }^{15}$

On the most sophisticated attitude-based theory, Heathwood's,

some bit of phenomenology counts as a pleasure just in case its subject has an intrinsic de re desire at time $t$ that it be occurring at $\mathrm{t}^{16}$

14. For defenses of felt-quality theories of pleasure, see Crisp (2006), Kagan (1992), Broad (1930), Duncker (1941), Smuts (2011), and Bramble (2013).

15. For defenses of attitude-based theories, see Alston (1967), Parfit (1984), Carson (2000), Feldman (2004), and Heathwood (2007).

16. Heathwood (2007). Note that this is my formulation of Heathwood's theory, not a direct quote. 
Felt-quality theories seem to have commonsense on their side. To many, it seems that we like or want pleasures because they are pleasurable, and hate and seek to avoid pains because they are painful. Why do I like or want the feeling of orgasm? Intuitively, it is because this feeling is pleasurable (or feels good). It does not feel good because I want it. Why would I want it if not because it feels good? Similarly, why do I hate the feeling of headache? It is because it is painful. It is not painful because I hate it. What is the feeling of headache even like without the painfulness? And why would I hate that? Attitude-based theories seem to get the order of explanation the wrong way around.

Despite this, most philosophers today favour attitude-based theories. This is mainly due to a widespread belief that felt-quality theories have been refuted by what has come to be known as the heterogeneity objection. This objection is as follows:

1. Felt-quality theories entail that all pleasures feel alike in some way.

2. All pleasures do not feel alike in some way.

Therefore,

3. Felt-quality theories are false.

Feldman, for example, writes:

Consider the warm, dry, slightly drowsy feeling of pleasure that you get while sunbathing on a quiet beach. By way of contrast, consider the cool, wet, invigorating feeling of pleasure that you get when drinking some cold, refreshing beer on a hot day.... [They] do not feel at all alike. (2004: 79)

He and others conclude that felt-quality theories are unacceptable.

Attitude-based theories, by contrast, have no trouble accounting for the felt diversity of pleasures. What does a pleasure of sunbathing have in common with one of drinking a cold beer on a hot day? Simply that its subject happens to like it or want it to be occurring.

I believe a hedonist should accept a felt-quality theory. ${ }^{17}$ This is for the following reason:

Only hedonism paired with a felt-quality theory is consistent with the right motivation for hedonism, the experience requirement. is best.

17. Note that I wish to remain neutral in this paper on the question of which felt-quality theory 
Suppose hedonism is true, and some attitude-based theory of pleasure is also true. In this case, there could be changes in well-being without changes in phenomenology. Why is this? It is because, on attitude-based theories, there can be changes in a person's pleasures and pains without changes in her phenomenology. On attitude-based theories, it is enough for there to be a change in one's pleasures and pains that there be some change in whether or the extent to which one intrinsically wants some bit of one's current phenomenology to be going on. For example, a bit of phenomenology that is for me right now neither pleasurable nor painful could become pleasurable simply in virtue of my coming to intrinsically want it to be going on.

It may be objected that, while it is true that, on attitude-based theories, there can be changes in pleasures and pains without changes in phenomenology, a hedonist is not committed to the view that every change in pleasures or pains affects well-being. A hedonist could say that it is only changes in pleasures and pains that do happen to involve changes in phenomenology that are ones that can affect a person's well-being. But this is hardly satisfactory. Such a hedonist would lack an explanation of why the experience requirement is true. She could not hold the appealing view that benefiting and harming require a change in phenomenology because hedonism is true.

A different response on behalf of attitude-based theorists is that intrinsically desiring some particular bit of phenomenology to be going on is a state that itself possesses a certain kind of phenomenology. If this is true, then changes in whether or the extent to which one wants some bit of one's phenomenology to be going on does necessarily involve some change in one's phenomenology. But even assuming that some desires can have phenomenology of their own (socalled 'intrinsic phenomenology'18), and that the intrinsic desire that is involved in making some bit of phenomenology count as a pleasure is among them, this would undermine the key motivation for holding an attitude-based theory in the first place, the heterogeneity objection. It would suggest that all pleasures do feel alike in some way-they would all share the phenomenology that is involved in the sort of desire that makes some bit of phenomenology count as a pleasure. ${ }^{19}$

Either way, then, the hedonist is going to have to contend with the heterogeneity objection. In light of this, it seems best simply to embrace the more commonsensical of the two kinds of theories-i.e., felt-quality ones - and attempt to respond to the heterogeneity objection.

Now, there is, I believe, a good response to the heterogeneity objection. This

18. For discussion, see Tye (1995) and Bayne and Montague (2011).

19. Admittedly, it is possible that what it is like to desire that a particular bit of phenomenology be occurring depends in part on the nature of the latter phenomenology, so that, on the view under consideration, there would not necessarily be any common feel to all pleasures. However, I will not further consider this possibility here. 
is that our knowledge of (the intrinsic features of) our own phenomenology is far from infallible. Not only can we have false beliefs about it, there are aspects of it that can be hard or even impossible for us to have true beliefs about. In a book and series of fine papers, Eric Schwitzgebel argues that

we make gross, enduring mistakes about even the most basic features of our currently ongoing conscious experience (or "phenomenology"), even in favorable circumstances of careful reflection, with distressing regularity ... The introspection of current conscious experience, far from being secure, nearly infallible, is faulty, untrustworthy, and misleading - not just possibly mistaken, but massively and pervasively. (2008: 247-259)

Schwitzgebel presents cases of mistaken beliefs about one's own visual imagery (Schwitzgebel 2002), auditory experience (Schwitzgebel 2000), and emotional experience. Concerning emotions, he writes,

Is emotional consciousness simply the experience of one's bodily arousal, and other bodily states, as William James (1981 [1890]) seems to suggest? Or, as most people think, can it include, or even be exhausted by, something less literally visceral? Is emotional experience consistently located in space (for example, particular places in the interior of one's head and body)? Can it have color-for instance, do we sometimes literally "see red" as part of being angry? Does it typically come and pass in a few moments (as Buddhists sometimes suggest), or does it tend to last awhile (as my English-speaking friends more commonly say)? If you're like me, you won't find all such questions trivially easy. You'll agree that someoneperhaps even yourself-could be mistaken about some of them, despite sincerely attempting to answer them, despite a history of introspection, despite maybe years of psychotherapy or meditation or self-reflection. (2008: 249-250)

He offers an example of a husband who is entirely oblivious to his own feelings of anger while doing the washing up:

My wife mentions that I seem to be angry about being stuck with the dishes again (despite the fact that doing the dishes makes me happy?). I deny it. I reflect; I sincerely attempt to discover whether I'm angry-I don't just reflexively defend myself but try to be the good self-psychologist my wife would like me to be-and still I don't see it. I don't think I'm angry. But I'm wrong, of course, as I usually am in such situations: My wife reads my face better than I introspect. Maybe I'm not quite boiling inside, but there's plenty of angry phenomenology to be discovered if I knew 
better how to look. Or do you think that every time we're wrong about our emotions, those emotions must be nonconscious, dispositional, not genuinely felt? Or felt and perfectly apprehended phenomenologically but somehow nonetheless mislabeled? Can't I also err more directly? (2008: 252)

Daniel Haybron, too, argues that

there are good reasons for doubting that any of us have a firm grasp on the quality of our experience of life, in particular its affective character. Possibly, many of us are profoundly ignorant about such matters, to the point that we often don't know whether we are happy or unhappy, or even whether our experience is pleasant or unpleasant. (2007: 395)

He asks us to consider, for example,

how a tense person will often learn of it only when receiving a massage, whereas stressed or anxious individuals may discover their emotional state only by attending to the physical symptoms of their distress. (2007: 398)

He goes on:

Perhaps you have lived with a refrigerator that often whined due to a bad bearing. If so, you might have found that, with time, you entirely ceased to notice the racket. But occasionally, when the compressor stopped, you did notice the sudden, glorious silence. You might also have noted, first, a painful headache, and second, that you'd had no idea how obnoxious the noise was - or that it was occurring at all-until it ceased. But obnoxious it was, and all the while it had been, unbeknownst to you, fouling your experience as you went about your business. In short, you'd been having an unpleasant experience without knowing it. Moreover, you might well have remained unaware of the noise even when reflecting on whether you were enjoying yourself: the problem here is ignorance-call it reflective blindness - and not, as some have suggested, the familiar sort of inattentiveness we find when only peripherally aware of something. In such cases we can bring our attention to the experience easily and at will. Here the failure of attention is much deeper: we are so lacking in awareness that we can't attend to the experience, at least not without prompting (as occurs when the noise suddenly changes). (2007: 400-401) 
If these philosophers are right, then our inability to introspect a common feel to all pleasures should not weigh all that heavily against felt-quality theories. ${ }^{20}$

I conclude that hedonism should be paired with a felt-quality, rather than an attitude-based, theory of pleasure and pain.

\section{The Philosophy of Swine}

The first objection to hedonism I want to consider is The Philosophy of Swine. J.S. Mill put it like this:

To suppose that life has ... no higher end than pleasure-no better and nobler object of desire and pursuit - [is] utterly mean and groveling . . . a doctrine worthy only of swine. ${ }^{21}$

Feldman makes the objection vivid in his example of Porky, a human being who

spends all his time in the pigsty, engaging in the most obscene sexual activities imaginable ... Porky derives great pleasure from these activities and the feelings they stimulate. Let us imagine that Porky happily carries on like this for many years. Imagine also that Porky has no human friends, has no other sources of pleasure, and has no interesting knowledge. Let us also imagine that Porky somehow avoids pains - he is never injured by the pigs, he does not come down with any barnyard diseases, he does not suffer from loneliness or boredom. (2004: 40)

Porky's life, for all its pleasures, does not seem high in well-being (compared with a normal human life). Importantly, this seems true no matter how long it lasts for. But how can a hedonist accept this?

We can formulate the worry more precisely as follows:

1. Hedonism entails that a pig's life (or a human life like Porky's) could be high in well-being (compared with a normal human life).

2. A pig's life (or a human life like Porky's) could not be high in wellbeing (compared with a normal human life).

Therefore,

3. Hedonism is false.

20. For further discussion, see Bramble (2013).

21. Mill (1998 Chapter II). 
Some hedonists have proposed biting the bullet-i.e., accepting that Porky is well off (compared with a normal human being). They have tried to explain away our intuition to the contrary in a number of ways. Heathwood, for example, suggests that we are inclined to feel this way only because we see that Porky's life is lacking in certain other respects, like "dignity, virtue, or achievement" (2006: 553), and our awareness of this is causing confusion.

But this is an extremely large bullet to bite. There is, I believe, a better response. A hedonist can explain why a life like Porky's is not high in well-being (compared with a normal human life). There are two reasons that it is not. Let me explain them in turn.

The first reason is that, while a Porky life contains many pleasures (and, let us assume, no pains), bodily pleasures like Porky's aren't especially pleasurable. The most pleasurable kinds of pleasures are not bodily ones, but rather some of the pleasures of love, learning, aesthetic appreciation, and so on. Porky is missing out on these highly pleasurable pleasures.

To attempt to convince you of this, I want to invoke a distinction from the previous section, between feeling or experiencing a pleasure (i.e., having some particular pleasurable phenomenology) and being aware of it. Now, certain pleasures, it seems, can be hard to attend to or to become aware of, while others can be difficult to miss. With this in mind, we can distinguish two senses in which a pleasure may be intense:

1. In the sense of being easy to attend to or even hard to miss.

2. In the sense of being highly pleasurable (i.e., being pleasurable to a high degree). ${ }^{22}$

Bodily pleasures, I want to suggest, are often extremely intense in the first sense. The pleasures of orgasm, massage, sunbathing, and so on, are (for most of us, in most cases) easy to attend to, and even hard to miss. It does not follow, however, that they are intense in the second sense, of being highly pleasurable. While the pleasures of orgasm, for example, typically feature prominently in one's consciousness, it may be that what one sees of them at these times is all that exists of them. By contrast, what one sees of the pleasures of love, learning, aesthetic appreciation, and so on, when one introspects them, may be merely the tip of the phenomenological iceberg, so to speak. There may be far more to these pleasures than typically meets the introspective eye.

So far I have identified these things merely as possibilities. Is there any reason to think that they are actually so? I believe there is. Consider some of the key

22. For related discussion, see Kagan (1992). 
factors that go into determining how easy it is to attend to or introspect a given pleasure:

1. Whether the pleasure has (or is associated with) a particular bodily location, or rather permeates one's entire experiential field. Permeating pleasures, other things being equal, are harder to attend to than pleasures having a particular bodily location. ${ }^{23}$

2. How the pleasure begins and develops. Pleasures that begin in only a small amount and then build up slowly over time are, other things being equal, harder to attend to than pleasures that come on suddenly. ${ }^{24}$

3. Whether the pleasure is a flow pleasure (i.e., involves mental absorption in some thing or activity). Flow pleasures are, other things being equal, harder to attend to than non-flow pleasures. ${ }^{25}$

Now, the pleasures of love, learning, and aesthetic appreciation, for the most part, are permeating pleasures (they lack specific bodily locations), build up slowly (as one gets to know a person, improves or builds upon one's knowledge or understanding of the world, or makes one's way through a novel, film, piece of music, etc.), and require that one's mind be somewhere other than on the pleasure (say, on one's friend, on the feature of the world one is learning about, or on the novel, film, or piece of music in question). ${ }^{26}$ As Sidgwick writes,

The pleasures of thought and study can only be enjoyed in the highest degree by those who have an ardour of curiosity which carries the mind temporarily away from self and its sensations. In all kinds of Art, again, the exercise of the creative faculty is attended by intense and exquisite pleasures: but it would seem that in order to get them, one must forget them: the genuine artist at work seems to have a predominant and temporarily absorbing desire for the realisation of his ideal of beauty. (1913: 49)

For these reasons, it seems plausible to think that there may be significantly more to the pleasures in question than one can easily introspect or attend to.

By contrast, bodily pleasures tend to have specific bodily locations, come on suddenly (as one eats, gets drunk, is caressed by one's lover, takes a drug, or collapses exhausted into bed), and in general do not require that one's mind be

23. For more on permeation, see Haybron (2007) and Bramble (2013).

24. See Haybron (2007).

25. See Csikszentmihalyi (1990).

26. There are exceptions. My claim is meant as a generalisation. 
somewhere other than on the pleasure-indeed, with bodily pleasures, attending to them often enhances the pleasure. It therefore seems reasonable to think that there is little or no more to most such pleasures than one can easily introspect or attend to.

Turn now to the second reason that a Porky life is not high in well-being (compared with a normal human life). This has to do with the value for one of diversity in one's pleasures. There are two parts to this reason:

1. Purely repeated pleasures - i.e., pleasures that introduce nothing qualitatively new in terms of pleasurableness into a person's life-add nothing in and of themselves to her lifetime well-being. ${ }^{27}$

2. A life of purely bodily pleasures, unlike one involving some of the pleasures of love, learning, aesthetic appreciation, etc., can involve very little qualitative diversity in pleasures. Its pleasures quickly become 'just more of the same'.

Let me defend these two claims, starting with (2).

I want to begin my defense of (2) by explaining why there is a great deal of qualitative diversity available in the pleasures of love, learning, and aesthetic appreciation. Consider, first, the pleasures of love. What it is like to come to know or love a particular person is not just the same as what it is like to come to know or love someone else. Each person is unique, making the pleasures associated with friendships and relationships qualitatively unique for the people involved. Moreover, there are many qualitatively new pleasures that are made possible by friendships and relationships as they evolve or deepen over time, or as those who are involved in them overcome challenges or share new experiences together.

Consider, next, the pleasures of learning. These also do not consist of just the same kind of pleasure (say, a warm glow or 'zing!') over and over again every time one learns a new fact. On the contrary, they have quite a different phenomenal character depending on what one has learned, the particular way in which one's mind has been opened up, and how one's new knowledge or understanding fits with what one already knows. Compare, for example, the pleasures of learning algebra with those of learning to ride a bike, watching David Attenborough's "The Life of Birds", understanding the basic problems of philosophy, or understanding some of the proposed solutions to these problems, etc. All of these, intuitively, are qualitatively very different.

Finally, consider the pleasures of appreciating great works of art, music,

27. For a related suggestion, see Lemos (2010). See also Brentano (1973). Note that I am here opposing what some have termed 'quantitative' hedonism - see Weijers (2011) and Moore (2013). 
literature, etc. Great novels and films typically transport one to places that no other work does, or involve characters that are so realistic that they are, like real people, unique, or offer insights or explore ideas in ways that no other work does. The pleasures associated with such works are correspondingly unique. Enjoyment of Hitchcock's Vertigo is very different from enjoyment of Kubrick's 2001: A Space Odyssey, which is very different again from enjoyment of a different Kubrick film, say, Full Metal Jacket. Similar remarks apply to great paintings, sculptures, and musical compositions. Enjoyment of a Chopin Nocturne differs greatly from enjoyment of The Beatles's She Loves You, which in turn differs greatly from enjoyment of a different Beatles song, say, I Am The Walrus. Moreover, one's enjoyment of a particular piece of music may itself deepen or evolve in wonderful ways over the course of weeks, months, or even years. One mark of a great film, novel, or song is that it tends to reward re-watching, re-reading, or re-listening. One finds there is often more to discover-including qualitatively new pleasures-each time one returns to it.

Turn now to purely bodily pleasures. While there is certainly some qualitative diversity available in these-the pleasures of sex, for example, differ in character from those of sunbathing-further instances of each of these sorts of pleasures seem rapidly to become just more of the same.

Heathwood (personal correspondence) objects to my claim as follows:

We can stipulate that Porky does all different things with the pigs, that he does these things on all different farms with all new scenery, that he eventually moves on to other animals, that he eventually starts supplementing the experiences with bondage equipment and drugs (all the while managing never to get bored, addicted, or filled with despair).

I accept that by changing Porky's life in these ways we might succeed in adding some new kinds of pleasures to it. But I doubt we can add very many. Porky's pleasures, after all, are not due to the unique personal characteristics of the pigs (as they might be if he were to have loving relationships with them), the beauty of the scenery (as they might be if he were any kind of aesthete), or his learning anything about himself or deepening in his understanding of the world. Any attempt to diversify Porky's pleasures by introducing him to new pigs, new settings for his sordid activities, and so on, would succeed in giving him, for the most part, merely new vehicles for what would be qualitatively the same pleasures.

Suppose this is granted. What can be said in defense of (1), the claim that purely repeated pleasures add nothing in and of themselves to lifetime wellbeing? Surely, you might insist, some purely repeated pleasures add at least something to some people's lifetime well-being. Is there really nothing of value for, say, Mary, in her enjoyment of her morning coffee, an enjoyment that pre- 
sumably is qualitatively identical each time? Or suppose I am walking down the street and pass my favourite flower (a gardenia), inhale, and greatly enjoy the scent. I may have experienced this pleasure a hundred times before, so often, in fact, that there is now nothing new about it. Still, the experience is glorious. I savour it, and am glad to be alive. Is this pleasure really of no worth for me because it has happened before?

There are two things to say in response to this worry. The first is that many pleasures that might seem on first glance to be purely repeated ones involve subtly new elements. They may be deeper or more intense than previous instances (as can happen, for example, when we become appreciators of something like coffee, wine, beer, certain kinds of food, etc.). Alternatively, the new context in which they are felt may add a new dimension to them. For example, what may seem to be a purely repeated pleasure of drinking coffee may be different if one is drinking the same coffee in a new setting (say, an interesting new cafe), with new friends, or with old friends but while discussing interesting new topics.

The second thing to say is that even pleasures that are purely repeated ones, while they add nothing in and of themselves to lifetime well-being, can have considerable instrumental value for us. Such pleasures can relax or stimulate us. They can rejuvenate or sustain us. They can help to clear our heads. They can vividly remind us of what pleasure can feel like, and so give us a hint of what qualitatively new pleasures may be on the horizon. They can help to make our lives interesting for us in the gaps between qualitatively new kinds of pleasures. They can, in all these ways, be a sort of oil for our joints. Without a good deal of purely repeated pleasures, we may never make it to the new ones. We must be careful not to confuse a pleasure's having instrumental value for one with its adding in and of itself to one's lifetime well-being.

I want to conclude this section by considering two important objections to my claim about the value of diversity in one's pleasures. The first is that, while diversity in pleasures is valuable, I have given the wrong account of why it is valuable. Diversity is valuable, it may be suggested, just in order to preserve the pleasurableness of one's experiences. Without some diversity, we tend to get bored or lose interest in things. The Beatles's music may be wonderful, but if one listens only to The Beatles, one will soon cease to enjoy their music as much as one did.

I accept that diversity is valuable for this reason. However, this is compatible with its having the other sort of value for us as well. Indeed, I suspect (though I admit this is pure speculation) that part of the reason we tend to lose interest in or gain less pleasure from things we have had a great deal of contact with lately is that we are implicitly aware that there are now fewer qualitatively new pleasures to be had from the thing in question, and so its value for us is reduced.

The second objection I want to consider is that a hedonist cannot consistently 
assign to diversity in one's pleasures the value I have assigned to it here. In particular, a hedonist cannot maintain that purely repeated pleasures have no value for a person. This is because a hedonist must say that the amount a given pleasure adds to one's lifetime well-being is directly proportional to its degree of pleasurableness. Otherwise, she is appealing to considerations other than the pleasurableness of a pleasure.

However, there is no good reason to think that a hedonist must appeal only to the degree to which a pleasure is pleasurable in explaining its value for one. So long as a candidate explanation does not breach what I have called the experience requirement, there is no reason a hedonist cannot embrace it. And there is nothing in my proposal about diversity that breaches this requirement.

I conclude that hedonism can accommodate our intuition that a life like Por$\mathrm{ky}^{\prime} \mathrm{s}$, no matter how long it lasts, is not high in well-being (compared with a normal human life).

\section{The Experience Machine}

In The Examined Life, Robert Nozick writes:

Imagine a machine that could give you any experience (or sequence of experiences) you might desire. When connected to this experience machine, you can have the experience of writing a great poem or bringing about world peace or loving someone and being loved in return. You can experience the felt pleasures of these things, how they feel "from the inside." You can program your experiences for ... the rest of your life. If your imagination is impoverished, you can use the library of suggestions extracted from biographies and enhanced by novelists and psychologists. You can live your fondest dreams "from the inside." Would you choose to do this for the rest of your life? ... Upon entering, you will not remember having done this; so no pleasures will get ruined by realizing they are machine-produced. (1989: 104)

If hedonism were true, Nozick suggests, then "plugging in would constitute the very best life, or tie for being the best, because all that matters about a life is how it feels from the inside" (1989: 105). Intuitively, however, Nozick continues, this is not so-there are alternatives that would be better for one. Therefore, hedonism is false. ${ }^{28}$

28. For a defense of this interpretation of Nozick, see Bramble (forthcoming). Others formulate Nozick's objection differently. See, for example, Weijers and Schouten (2013) and Feldman (2011). 
What should we make of Nozick's argument? The standard response to it by hedonists is to accept that plugging in would be best for one, and then to try to explain why some of us are inclined to feel otherwise. For example, some may be failing to keep firmly and vividly in mind various important features of the case (such as that one's experiences in the machine would truly be reality-quality, or that the machine is guaranteed not to malfunction). Others may be allowing their intuitions concerning related matters (say, whether it is best simpliciter or morally permissible for one to plug in to the machine) to interfere with or contaminate their intuitions concerning well-being. Others still may be being misled by an irrational fear of technology, feeling of disgust, or bias they possess in favour of preserving the status quo. ${ }^{29}$

These are all interesting suggestions. However, they seem to me not fully to account for our feelings here. When we keep in mind these important features, focus just on well-being, and set aside our fears, biases, etc. - all things that seem possible for many of us to do-we continue to feel that plugging in would not be best for a person. ${ }^{30}$

I want to suggest a different response. This is that hedonism might be compatible with the claim that plugging in would not be best for one. Indeed, hedonism might offer the best explanation of why it would not be best for one to plug in. How could this be true? The answer, I believe, is that Nozick's machine might be unable to give one the most intense and diverse pleasures of all: the full range of the pleasures of love and friendship in the long run.

Consider what is necessary in order to experience these pleasures in real life. It is a familiar fact that if one's close friend, partner, or family member, does not truly love one (where such love includes feeling real affection for one), theneven if this person thinks they truly love one, or is trying their hardest to-one's interactions with them will be missing something important. Their behaviour toward and around one, both bodily and verbal, will be 'off' somehow. They will fail to say quite the right things, display quite the right facial expressions, or perform quite the right gestures or actions, at the right times, to make one feel as a close friend or loved one ideally should. They might, for example, be overly impatient with one, or, at different times, too patient. They might misread one's emotional cues and so miss opportunities to comfort or amuse one. They might simply bore one. While it is possible they could fluke the right behaviours for a while, it is extremely unlikely they could do so in the long run. What's more, all

29. For a more detailed description of these responses, see Bramble (in press). See also Sumner (1996), Hewitt (2010), Kolber (1994), De Brigard (2010), and Weijers (2014).

30. Some have suggested, intriguingly, that our intuitions here are merely the product of evolution or hedonic-conditioning, and so should be disregarded. See, for example, Crisp (2006), Silverstein (2000), Lazari-Radek and Singer (2014), De Brigard (2010), and Weijers (2014). For some challenges for these suggestions, see Bramble (forthcoming). 
this could take place without one's realising that anything was awry. It might take years, and the counsel of friends who do love one, to understand it. What is my point? Simply that in real life, the pleasures of love require love.

What about in a more controlled setting? Could a troupe of highly skilled actors produce the relevant behaviours (the ones required to give one the pleasures I am talking about)? Again, it is hard to imagine how they could. Consider the character of Truman Burbank in the film The Truman Show, who from birth has been the star of his own reality TV show without knowing it. Truman is miserable because, while the actors around him are all at the top of their game, and their lines are carefully crafted by the brilliant Christof, he has never had contact with anyone who truly loves or cares about him. ${ }^{31}$ The moment he encounters somebody on the set of his TV show who is not acting, somebody who has real affection for him - a woman named Lauren - he is instinctively drawn to her. She seems to give him something that he has never before hadsomething experiential.

Return now to Nozick's machine. It seems possible that, just as fake friends and a troupe of highly skilled actors could not be adequate to give one the full range of the pleasures of love and friendship in the long run, so too the experience machine might necessarily fall short. Since there is no-one either running the machine or inside it along with one who truly loves one, there is no-one in this whole setup who understands one in only the way that a true friend or loved one can-i.e., the way, I have suggested, that is required to behave in precisely the right ways around one in order to give one the pleasures of love.

If this is true, then a hedonist can say that the reason that plugging in is not best for one is that it would deprive one of the full range of the pleasures of love and friendship in the long run, some of which are so intense (in the sense of being pleasurable to a high degree) and diverse that their loss could not be compensated for by any amount of other pleasures one could get in the machine. ${ }^{32}$

As further evidence of this explanation, consider that, for many of us, the main reason plugging in seems not best for one is that it would involve permanent separation from other real conscious selves. Many of us would happily plug in all together to a 'communal' machine, in which we could each live whatever sort of life we wanted whilst continuing to interact with our existing friends and loved ones (who would occupy this virtual world along with us ${ }^{33}$ ). Similarly, it is com-

31. Christof claims to love him - but we can tell that this isn't so by Christof's willingness to allow Truman to remain in the TV program. In any case, Truman never comes into direct contact with Christof (until his moment of escape).

32. See Section 5 above for my reasons for thinking that the pleasures of love and friendship might include pleasures this intense and diverse.

33. The details of how such a communal machine would work are, needless to say, complicated. I will not attempt to go into them here. 
mon for people to say that they would plug in to Nozick's machine if they had no friends or loved ones in the real world, or were facing a life of solitary confinement. ${ }^{34} \mathrm{My}$ explanation offers a straightforward account of why these things are so. Permanent separation from other real selves is so bad for one, on my view, because it necessarily has experiential consequences for one.

By contrast, it is unclear how rival explanations of why plugging in would not be best for one could account for the apparent central importance of remaining in contact with other real selves. One might try to say-as Nozick, for instance, might - that permanent separation from other real selves is so bad for one because connection with reality is intrinsically good for one, and reality includes other real people. But why should it be just this one part of reality that is so vital for us to remain in contact with?

I want now to consider an important objection to the explanation I have provided. This is that I am simply being unimaginative. A sufficiently sophisticated machine could work out what behaviours were needed to give one the relevant pleasures. ${ }^{35}$

Perhaps this is right. Let's be charitable and suppose that it is. In this case, I believe, it would be best for one to plug in to the machine. Is this an intuitive claim? I accept that it might not be. But this fact, it seems to me, does not tell all that strongly - if at all-against hedonism, since it is one thing to suppose or stipulate that the machine could work out the relevant behaviours, and quite another to have some meaningful or clear grasp of how it could do so. It is only, I believe, if we were to have the latter sort of grasp that we would find it intuitive that it would be best for someone to plug in. While it is relatively easy to imagine a machine's delivering truly reality-quality experiences, not malfunctioning, etc., it is not so easy to imagine how a machine like Nozick's could be designed in such a way as to work out these behaviours. Without such a clear idea, our intuitions here are virtually worthless. ${ }^{36}$

As evidence of this, consider:

34. Even Nozick writes: "One of the distressing things about the experience machine, as described, is that you are alone in your particular illusion. (Is it more distressing that the others do not share your "world" or that you are cut off from the one they do share?)" (1989: 107, my emphasis).

35. An anonymous reviewer suggests to me that the recent film Ex Machina clearly illustrates how an AI would be able to give one the pleasures of love. However, it is doubtful that the pleasures the AI depicted in this particular film gives the human protagonist are those of love or friendship, as distinct from those of lust and awe. Furthermore, even if it were plausible that she gives him some of the pleasures of love, it is by no means clear that she could give him the full range of the pleasures of love in the long run.

36. It may be easier to imagine the machine, on a particular occasion, fluking the relevant behaviours. In such a case, it actually seems to me fairly intuitive that it would be best for one to have plugged in. But, even here, it requires quite an imaginative feat to hold everything in one's mind long enough to have an intuition that is worth anything. 
The Same-Experiences Machine. There is a machine that would give you the exact same future course of experiences that you would have if you were not to plug in. Here's how it works: If you plug in, the machine will calculate the complete way that the universe would have gone had you not plugged in to it, including all the experiences, down to their finest details, you would have had. ${ }^{37}$ It then feeds you these very experiences over the same period of time that you would have had them for in the real world. Note that upon entering, you will not remember having chosen to plug in. Indeed, you might believe that you have chosen not to plug in.

Unlike with Nozick's machine, it is quite clear how The Same-Experience Machine could give one the full range of the pleasures of love and friendship in the long run (assuming determinism is true). Now, ask yourself: Does it seem any worse for you to plug in to this machine than to remain in reality? ${ }^{38}$ I would suggest not. Intuitively, it makes no difference to one's well-being whether one plugs in or not. I accept that not everyone will share this intuition. But, at the very least, I hope that the reader feels that it would be far more acceptable to plug into The Same-Experiences Machine than a machine like Nozick's. ${ }^{3940}$

I want to conclude by showing how my response to Nozick's objection allows us to respond to a related objection to hedonism, the Deceived Businessman. Here is the case (nicely told by Feldman):

The ... businessman is happy because, as he thinks, his career is going well, he is respected in his community, and he has a loving family ... [All] of his assumptions are false. [He] is in fact held in utter contempt by his colleagues, deeply deceived by his adulterous wife, and hated by his children. Each has his or her reasons for engaging in the deception, but the result is the same: the businessman's happiness is completely dependent upon his widespread misapprehension of his circumstances. If he

37. Assume that the universe is deterministic.

38. Again, it is important here to consider only what seems to be in your own interests, and not other matters like what would be best simpliciter.

39. It may be suggested that this is because, in The Same-Experiences Machine, one would still have a connection to what would have been reality. But this is an odd claim, and would be quite different from Nozick's (that a connection with reality itself is intrinsically valuable for one).

40. What about a case where two individuals' lives are experientially identical from birth to death, but where only one is connected to reality (suppose the experiences of one person's life are somehow copied and played in their entirety, like a video tape, to another person)? (Such a case has recently been suggested by Crisp 2006; Hawkins 2015; and Lin in press). I confess I find it hard to have clear intuitions about such a case, mainly because I find it tempting to think that we would have here not two numerically distinct individuals, but rather just the one (for, it seems to me, there would be only one stream of experiences). I also have worries over whether one could just copy someone's experiences in their entirety and play them to another in this way. Perhaps experiences of free choice, for example, are not duplicable in this way. 
knew the truth about his colleagues, his wife, and his children, he would be miserable. (2004: 41 $)^{41}$

The worry for hedonism is that, while this businessman is perfectly happy, he does not seem at all well off. At the very least, he seems worse off than somebody whose life is identical from the inside, but whose family does love him.

But it seems to me practically impossible to imagine this man's family's lack of love for him not impinging in various important ways on his experiences. No family could be that good at faking it (and certainly not for years). Genuine love manifests in all sorts of spontaneous actions, gestures, and expressions. While the deceived businessman might never suspect that his family does not really love him, and might even (in some sense) feel loved, the quality of his experiences would almost certainly be affected. He would not be getting the full range of the pleasures of love and friendship, and moreover would likely be feeling pains of alienation or of failing to understand other people or the world around him.

Suppose that the man in question was severely autistic, and so (let us assume) incapable of experiencing anything like the range of pleasures of love that you and I experience in our lives. In this case, whether or not his family really loves him might not affect his life from the inside one bit. Now, ask yourself, does it still seem that he is made worse off by his family's not really loving him? I would suggest not. There is a sense in which if his family really did love him, their love would be wasted on him.

\section{The Resonance Constraint}

Many philosophers accept something that has come to be known as the resonance constraint (on an adequate theory of well-being). According to this constraint, whatever is good for someone must resonate with or appeal to this particular person in some way. As Peter Railton famously puts it:

What is intrinsically valuable for a person must have a connection with what he would find in some degree compelling or attractive, at least if he were rational and aware. It would be an intolerably alienated conception of someone's good to imagine that it might fail in any such way to engage him. (1986: 9) ${ }^{42}$

This claim is now the standard reason in the literature to reject so-called objective list theories of well-being, on which things such as friendship, knowledge,

41. See also Kagan (1994).

42. See also Rosati (1996). 
achievement, etc., can be good for a person whether or not this person has any desire at all for them. How can achievement be good for somebody who cares nothing for it?

Recently, a number of philosophers have suggested that the objection applies equally to hedonism. Hedonism, after all, it is noted, is a list theory with a very small list. How can a life of pleasure be good for those who care nothing for pleasure? Hedonism alienates these individuals from their good (whatever it may turn out to be). 43

How should a hedonist respond to this objection? Some have argued that hedonism can satisfy the resonance constraint. Heathwood, for example, suggests that hedonists can satisfy it by adopting an attitude-based theory of pleasure. He writes:

[I]f pleasure constitutively involves desire, then what is good for us, according to hedonism, will automatically bear a connection to what engages us, or resonates with us. (Heathwood 2016)

However, as I claimed in Section 4, hedonists can adopt an attitude-based theory of pleasure only at the cost of giving up the proper motivation for hedonism.

There is, I believe, a better response: Oppose the resonance constraint. There are compelling counterexamples to it. Consider:

Testy Tom. It is 1964, and Beatlemania is sweeping the globe. Tom is a grumpy old man who disapproves of modern rock music. He has heard some of The Beatles's music, and regards it as utterly without merit, and, moreover, liable to corrupt the youth. He desires not to hear it, and certainly not to enjoy it. Nonetheless, his wife insists on playing it, and so Tom (who cannot easily leave the house due to an injury) must listen several times per week. He does not like this one bit. One day, to his extreme annoyance, he finds himself tapping his toes and humming along to Please Please Me. He is enjoying The Beatles's music. Is he glad? No, he is horrified!

Is Tom's pleasure of listening to Please Please Me in any way good for him? Intuitively, yes. That is, at the end of the day, this pleasure will have made him better off in at least one respect in his life considered as a whole than he would have been if he had not heard and enjoyed this song. Of course, it might still have been wrong for his wife to impose it upon him. Moreover, it might have been worse on balance for Tom that he was made to hear this music, given the

43. See, for example, Tiberius and Plakias (2010). 
stress or anxiety it has caused him. But none of this shows that it doesn't make him better off in one respect.

Consider, next:

Disgruntled Dick. Dick is a retired military colonel who has renounced the pleasures of love. He considers such feelings to be weak and worthless. One day, his long lost daughter gets in touch and re-enters his life. He finds himself feeling glimmers of true closeness and love for the first time in his life. Is Dick glad? Not one bit! He sincerely wishes, in every part of his being, that he did not feel these things.

Despite Dick's unambiguous opposition to these pleasurable feelings, it seems possible that they could be the best things that ever happen to him.

Consider, finally, the pleasures of flow mentioned earlier (of, say, meditating, being immersed in playing tennis, listening absorbedly to a symphony or rock album, etc.), or the pleasures involved in dreams. These pleasures, it seems, cannot be known by us with sufficient clarity for our wanting them to be a necessary condition of their being good for us. And yet they seem to have considerable value for us indeed.

It may be asked, if the resonance constraint is false, then why do so many philosophers find it plausible? Part of the reason, I suspect, has to do with the fact that, for many sorts of things, there is a sense in which we must like or want them if they are to be good for us. Take flavours of ice cream. There is no point in choosing peppermint if you dislike that sort of flavour (and, what's more, would not even come to like it if you were to give it more of a chance). Similarly, if you don't like horror movies, it is doubtful you would be well served by going to see one. But these cases, properly understood, are not cases of desires or preferences placing limits on what can be good for us. Talk of 'liking' and 'disliking' here seems rather to be elliptical for talk of what brings us pleasure and pain. In saying you dislike peppermint, you're saying that it doesn't taste good to you (affords you no pleasurable experience), and in fact, it tastes bad (affords you unpleasurable experience). In saying you don't like horror movies, you're saying you get no enjoyment from them. And so on. So, while there is a sense in which, in these special sort of cases ("matters of mere taste", as they have been called44), one must like something if it is to be good for one, this is consistent with hedonism. Indeed, hedonism nicely explains why there is some truth in it.

Another part of the reason, I believe, that so many people are attracted to the resonance constraint has to do with the fact that, within certain limits, people ought to be allowed maximal freedom to pursue their desires or chosen conception of the good. We should not impose ways of life on people, even if we

44. See, for example, Sobel (2005). 
know that these ways of life would be highly pleasurable for those concerned. Perhaps, when it comes to some philosophers, their attraction to the resonance constraint lies in a commitment to this kind of anti-paternalism. They might, in other words, be confusing the idea that we should be allowed a great deal of freedom in choosing our own lifestyle with the idea that our attitudes determine what is good for us. But this is, to be sure, a confusion. The truth of hedonism would not entail that it is sometimes permissible to force people to do something just because it would be pleasurable for them. 45

I conclude that a hedonist has a good reply available to The Resonance Constraint objection - she should oppose this constraint.

\section{Conclusion}

In this paper, I have provided a new defense of hedonism about well-being. At the heart of this defense have been five main claims:

1. That hedonism should be paired with a felt-quality, rather than an attitude-based, theory of pleasure and pain.

2. That there is an important difference between the degree to which a pleasure is pleasurable and the ease with which one can introspect it.

3. That diversity in our pleasures has a special value for us.

4. That Nozick's experience machine might be unable to give one the full range of the pleasures of love and friendship in the long run (or at least that it is extremely hard to imagine how it could do so).

5. That a hedonist should oppose, rather than attempt to satisfy, the resonance constraint.

We can sum up the version of hedonism I have defended as follows:

For any two individuals, $S$ and $S^{*}, S$ was better off in some respect in her life considered as a whole than $S^{*}$ if and only if

(i) S felt some kind of pleasurable phenomenology that $S^{*}$ did not feel, or some kind of pleasurable phenomenology that $S^{*}$ felt, but in a higher degree than $S^{*}$ felt it, or

45. Among the reasons for this is, as Mill famously pointed out, that such force is unlikely to lead to especially pleasurable outcomes. 
(ii) $S^{*}$ felt some kind of painful phenomenology that $S$ did not feel, or some kind of painful phenomenology that $S$ felt, but in a higher degree than $S$ felt it.

The most fortunate lives, on this theory, are, roughly, those with a very great variety of highly pleasurable pleasures and very little variety of highly painful pains.

Why should we accept this theory? Because only it respects the experience requirement while having the resources to deal with the three major objections to hedonism.

\section{Acknowledgements}

I wish to thank two anonymous reviewers for Ergo for their very helpful comments.

\section{References}

Alston, William (1968). Pleasure. In Paul Edwards (Ed.), The Encyclopedia of Philosophy. Collier-Macmillan.

Bayne, Tim and Michelle Montague (2011). Cognitive Phenomenology: An Introduction. In Tim Bayne and Michelle Montague (Eds.), Cognitive Phenomenology (1-34). Oxford University Press. http://dx.doi.org/10.1093/acprof:0so/9780199579938.003.0001

Bradley, Ben (2009). Well-being and Death. Oxford University Press. http://dx.doi. org/10.1093/acprof:0so/9780199557967.001.1

Bramble, Ben (2013). The Distinctive Feeling Theory of Pleasure. Philosophical Studies, 162(2), 201-217. http://dx.doi.org/10.1007/s11098-011-9755-9

Bramble, Ben (2014). Whole-Life Welfarism. American Philosophical Quarterly, 51(1), 63-74

Bramble, Ben. (2016). The Passing of Temporal Well-Being. Manuscript in preparation.

Bramble, Ben (in press). The Experience Machine. Philosophy Compass.

Brentano, Franz (1973). The Foundation and Construction of Ethics. Routledge and Kegan Paul.

Brink, David O. (2010). Prospects for Temporal Neutrality. In Craig Callender (Ed.), The Oxford Handbook on Time (353-381). Oxford University Press.

Broome, John (2004). The Value of Living Longer. In Sudhir Anand, Fabienne Peter, and Amartya Sen (Eds.), Public Health, Ethics, and Equity (243-26o). Oxford University Press.

Broad, C. D. (1930). Five Types of Ethical Theory. Routledge and Kegan Paul.

Campbell, Stephen (2015). When the Shape of a Life Matters. Ethical Theory and Moral Practice, 18(3), 565-75 http://dx.doi.org/10.1007/s10677-014-9540-x

Carson, T. L. (2000). Value and the Good Life. University of Notre Dame Press. 
Crisp, Roger (2006). Reasons and the Good. Oxford University Press. http://dx.doi. org/10.1093/acprof:0so/9780199290338.001.0001

Csikszentmihalyi, Mihaly (1990). Flow: The Psychology of Optimal Experience. Harper and Row.

De Brigard, Felipe (2010). If You Like It, Does It Matter If It's Real? Philosophical Psychology, 23(1), 43-57. http://dx.doi.org/10.1080/09515080903532290

Dorsey, Dale (2011). The Hedonist's Dilemma. Journal of Moral Philosophy, 8(2), 173-196. http://dx.doi.org/10.1163/174552411X563240

Duncker, Karl (1941). On Pleasure, Emotion, and Striving. Philosophy and Phenomenological Research, 1(4), 391-430. http://dx.doi.org/10.2307/2103143

Feldman, Fred (2004). Pleasure and the Good Life. Oxford University Press. http://dx.doi. org/10.1093/019926516x.001.0001

Griffin, James (1986). Well-Being. Clarendon Press.

Harman, Elizabeth (2004). Can We Harm and Benefit in Creating? Philosophical Perspectives, 18(1), 89-113. http://dx.doi.org/10.1111/j.1520-8583.2004.00022.x

Haybron, Daniel M. (2007). Do We Know How Happy We Are? On Some Limits of Affective Introspection and Recall. Nô̂s, 41(3), 394-428. http://dx.doi.org/10.1111/j.1468-0068.2007.00653.x

Heathwood, Chris (2006). Desire Satisfactionism and Hedonism. Philosophical Studies, 128(3), 539-563 http://dx.doi.org/10.1007/s11098-004-7817-y

Heathwood, Chris (2007). The Reduction of Sensory Pleasure to Desire. Philosophical Studies, 133(1), 23-44. http://dx.doi.org/10.1007/s11098-006-9004-9

Heathwood, Chris (2011). Preferentism and Self Sacrifice. Pacific Philosophical Quarterly, 92(1), 18-38. http://dx.doi.org/10.1111/j.1468-0114.2010.01384.x

Heathwood, Chris (2016). Subjective Desire Satisfactionism. Manuscript in preparation.

Hewitt, Sharon (2010). What Do Our Intuitions About The Experience Machine Really Tell Us About Hedonism? Philosophical Studies, 151(3), 331-349. http://dx.doi. org/10.1007/s11098-009-9440-4

Kagan, Shelly (1992). The Limits of Well-Being. In Ellen F. Paul, Fred D. Miller, and Jeffrey Paul (Eds.), The Good Life and the Human Good (169-89). Cambridge University Press. http://dx.doi.org/10.1017/s0265052500001461

Kagan, Shelly (1994). Me and My Life. Proceedings of the Aristotelian Society, 94, 309-324. http://dx.doi.org/10.1093/aristotelian/94.1.309

Kauppinen, Antti (2012). Meaningfulness and Time. Philosophy and Phenomenological Research, 84(2), 345-77. http://dx.doi.org/10.1111/j.1933-1592.2010.00490.x

Kolber, Adam (1994). Mental Statism and the Experience Machine. Bard Journal of Social Sciences, 3(3-4), 10-17.

Korsgaard, Christine. M. (1996). The Sources of Normativity. Cambridge University Press. http://dx.doi.org/10.1017/cbo9780511554476

de Lazari-Radek, Katarzyna, and Peter Singer (2014). The Point of View of the Universe: Sidgwick and Contemporary Ethics. Oxford University Press. http://dx.doi.org/10.1093/ acprof:0so/9780199603695.001.0001

Lemos, Noah (2010). Summation, Variety, and Indeterminate Value. Ethical Theory and Moral Practice, 13(1), 33-44. http://dx.doi.org/10.1007/s10677-009-9171-9

Lin, Eden (in press). How to Use The Experience Machine. Utilitas. http://dx.doi. org/10.1017/s0953820815000424 
Lukas, Mark (2009). Desire Satisfactionism and The Problem of Irrelevant Desires. Journal of Ethics \& Social Philosophy, 4(2), 1-24.

McMahan, Jeff (2002). The Ethics of Killing. Oxford University Press. http://dx.doi. org/10.1093/0195079981.001.0001

Mill, John S. (1998). Utilitarianism. Roger Crisp (Ed.). Oxford University Press.

Moore, Andrew (2013). Hedonism. In Edward N. Zalta (Ed.), The Stanford Encyclopedia of Philosophy. Retrieved from http://plato.stanford.edu/archives/win2013/entries/hedonism/

Mulgan, Tim (2006). Future People. Oxford University Press. http://dx.doi. org/10.1093/019928220x.001.0001

Nozick, Robert (1989). The Examined Life. Simon \& Schuster.

Parfit, Derek (1984). Reasons and Persons. Oxford: Oxford University Press.

Portmore, Douglas (2007). Well-Being, Achievement, and Self-Sacrifice. Journal of Ethics $\mathcal{E}$ Social Philosophy, 2(2), 1-28.

Rachels, Stuart (2004). Six Theses About Pleasure. Philosophical Perspectives, 18(1), 247267. http://dx.doi.org/10.1111/j.1520-8583.2004.00028.x

Raibley, Jason (2012). Welfare over Time and the Case for Holism. Philosophical Papers, 41(2), 239-265. http://dx.doi.org/10.108o/05568641.2012.699174

Railton, Peter (2003). Facts and Values. In Facts, Values, and Norms (43-68). Cambridge University Press. http://dx.doi.org/10.1017/CBO9780511613982.003

Rosati, Connie S. (1996). Internalism and the Good for A Person. Ethics, 106(2), 297-326. http://dx.doi.org/10.1086/233619

Schwitzgebel, Eric (2008). The Unreliability of Naive Introspection. Philosophical Review, 117(2), 245-273. http://dx.doi.org/10.1215/00318108-2007-037

Shiffrin, Seana (1999). Wrongful Life, Procreative Responsibility, and the Significance of Harm, Legal Theory, 5(2), 117-48. http://dx.doi.org/10.1017/S1352325299052015

Sidgwick, Henry (1913). The Methods of Ethics. Macmillan.

Silverstein, Matthew (2000). In Defense of Happiness: A Response to the Experience Machine. Social Theory and Practice, 26(2), 279-300. http://dx.doi.org/10.5840/soctheorpract 200026225

Smuts, Aaron (2011). The Feels Good Theory of Pleasure. Philosophical Studies, 155(2): 241-265. http://dx.doi.org/10.1007/s11098-010-9566-4

Sobel, David (2005). Pain for Objectivists: The Case of Matters of Mere Taste. Ethical Theory and Moral Practice, 8, 437-57. http://dx.doi.org/10.1007/s10677-005-8839-Z

Sumner, L. W. (1996). Well-Being, Happiness, and Ethics. Oxford University Press.

Tiberius, Valerie and Alexandra Plakias (2010). Well-Being. In John Doris (Ed.), The Moral Psychology Handbook (402-432). Oxford University Press. http://dx.doi.org/10.1093/ac prof:0so/9780199582143.003.0013

Tye, Michael (1995). Ten Problems of Consciousness. MIT Press.

Velleman, David (2000). Well-Being and Time. In The Possibility of Practical Reason (5684). Oxford University Press.

Weijers, Dan and Vanessa Schouten (2013). An Assessment of Recent Responses to the Experience Machine Objection to Hedonism. Journal of Value Inquiry, 47(4), 461-482 http://dx.doi.org/10.1007/s10790-013-9395-8

Weijers, Dan (2014). Nozick's Experience Machine Is Dead, Long Live the Experience Machine! Philosophical Psychology, 27(4), 513-35. http://dx.doi.org/10.1080/09515089 .2012 .757889 